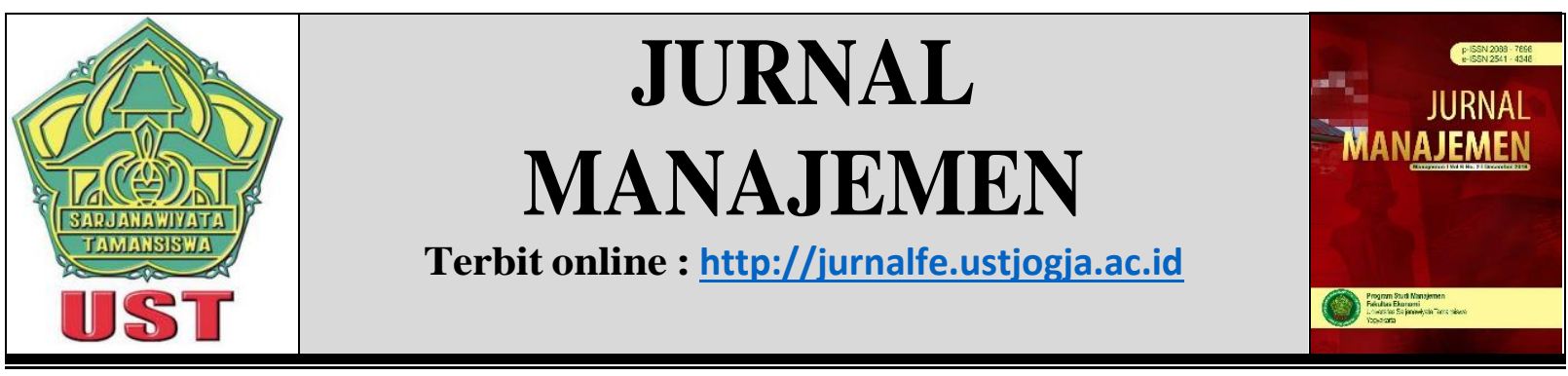

\title{
PENGARUH BUDAYA KERJA, PELATIHAN, DAN MOTIVASI TERHADAP ORGANIZATIONAL CITIZENSHIP BEHAVIOR PENGRAJIN BATIK DI SENTRA BATIK GIRILOYO YOGYAKARTA
}

\author{
Yosoa Satriadi Prihanto ${ }^{1}$ \\ Prayekti $^{2}$ \\ Universitas Sarjanawiyata Tamansiswa ${ }^{1,2}$ \\ Korespondensi: yosoasatriadip@gmail.com
}

\begin{tabular}{|c|c|}
\hline Informasi Naskah & Abstrak \\
\hline Diterima: & The purpose of this study was to analyze the influence work culture on \\
\hline 1 Juni 2018 & $O C B$, influence training on $O C B$, influence motivation on $O C B$, and \\
\hline Revisi: & influence work culture, training, and motivation on $O C B$ craftsman \\
\hline 18 Juni 2018 & batik at Giriloyo, Yogyakarta. Data collection using a questionnaire, \\
\hline Terbit: & while data analysis techniques using multiple regression analysis by the \\
\hline 27 Juni 2018 & F-test and T-test, and the classical assumption test of multicollinearity \\
\hline $\begin{array}{l}\text { Kata Kunci: } \begin{array}{r}\text { work } \\
\text { culture, } \\
\text { motivation, } O C B\end{array} \\
\text { training, }\end{array}$ & $\begin{array}{l}\text { test, normality test, and heteroscedasticity. The results with level of } \\
\text { significance } 5 \% \text { or } 0,05 \text { showed that work culture haven't significant } \\
\text { effect on } O C B(0,460>0,05) \text {, training have significant effect on } \\
\text { OCB }(0.004<0,05), \text { motivation have significant effect on } O C B(0.038< \\
0,05) \text {, and work culture, training, and motivation has significant effect } \\
\text { on OCB craftsman batik at Giriloyo, Yogyakarta. }\end{array}$ \\
\hline
\end{tabular}

\section{PENDAHULUAN}

Saat ini batik mulai berkembang dari waktu ke waktu. Batik menjadi lebih bebas dikreasikan dalam bentuk apapun. Saat ini batik lebih beragam. Keberagaman tersebut meliputi keberagaman motif batik yang semakin lama semakin berkembang, keberagaman warna batik yang semakin lama semakin menarik warnanya, serta keberagaman jenis bahan, teknik, dan desain busananya. Salah satu sentra batik yang ada di Yogyakarta ialah sentra batik Giriloyo yang terletak di Imogiri, Bantul.

Pada era ini, para pengrajin batik harus siap beradaptasi dan memperkuat diri agar dapat bersaing sehingga mampu menjawab semua tantangan di masa yang akan datang. Organizational Citizenship Behavior menjadi salah satu bukti adanya kerjasama tim yang solid di dalam sebuah kelompok. Organizational Citizenship Behavior (OCB) adalah sikap membantu yang ditunjukkan oleh anggota organisasi, yang sifatnya konstruktif, dihargai oleh perusahaan tapi tidak secara langsung berhubungan dengan produktivitas individu. Organizational Citizenship Behavior (OCB) dapat mengurangi terjadinya perselisihan dan meningkatkan efisiensi pekerjaan. Dengan demikian secara tidak langsung bila perilaku tersebut dimiliki para pengrajin batik di sentra batik Giriloyo maka dapat menumbuhkan hasil 
yang positif bagi kelompok batik mereka, baik untuk tujuan kelompok itu sendiri maupun untuk kehidupan sosial dalam kelompok tersebut.

Di dalam era yang semakin kompetitif dan persaingan yang semakin terasa, budaya kerja berkembang sesuai perkembangan lingkungan. Budaya kerja merupakan suatu persepsi bersama yang dianut oleh anggota-anggota kelompok itu atau sistem makna bersama yang dihargai oleh organisasi. Karakteristik-karakteristik inilah yang akan membedakan suatu kelompok dengan kelompok lainnya. Di sisi lain, budaya kerja memiliki dampak yang kuat pada perilaku anggota yang diikuti dengan efektivitas. Oleh karena itu, tentunya kelompok pengrajin batik Giriloyo perlu membangun budaya kerja yang kuat bersama dengan anggota karena faktor ini memiliki pengaruh akan munculnya perilaku positif di antara anggota.

Dalam persaingan usaha batik yang saat ini semakin tinggi maka para pengrajin batik harus meningkatkan keterampilan, untuk meningkatkan keterampilan para pengrajin maka diperlukan suatu pelatihan. Sentra batik Giriloyo yang sudah berdiri sejak tahun 1654 dan memiliki khas motif pada batiknya bekerja sama dengan LSM (Lembaga Swadaya Masyarakat) melakukan pelatihan bagi para pembatik di Giriloyo. Pelatihan yang bekerja sama dengan LSM tersebut meliputi pewarnaan dan pengembangan motif batik.

Namun, budaya kerja yang bagus dan pelatihan yang memadai tidak akan menghasilkan hasil yang maksimal bila tidak ada motivasi dari pekerja itu sendiri. Penelitian ini mencoba untuk memperluas pemahaman mengenai pengaruh budaya kerja, pelatihan, dan motivasi terhadap Organizational Citizenship Behavior $(O C B)$ pengrajin batik di sentra batik Giriloyo Yogyakarta.

Karena pentingnya pengembangan sentra Batik Tulis di Yogyakarta maka penelitian ini menguji secara empiris budaya kerja berpengaruh terhadap Organizational Citizenship Behavior (OCB), pelatihan berpengaruh terhadap Organizational Citizenship Behavior (OCB ), motivasi berpengaruh terhadap Organizational Citizenship Behavior (OCB) dan budaya kerja, pelatihan, dan motivasi secara simultan berpengaruh terhadap Organizational Citizenship Behavior $(O C B)$ pengrajin batik di sentra batik Giriloyo Yogyakarta.

\section{Tinjauan Teori Dan Hipotesis}

Menurut Hadari Nawawi (2003) budaya kerja adalah kebiasaan yang dilakukan berulangulang oleh pegawai dalam suatu organisasi, pelanggaraan terhadap kebiasaan ini memang tidak ada sangsi tegas, namun dari pelaku organisasi secara moral telah menyepakati bahwa kebiasaan tersebut merupakan kebiasaan yang harus ditaati dalam rangka pelaksanaan pekerjaan untuk mencapai tujuan. Dessler (2004) mengatakan bahwa pelatihan adalah proses mengajarkan karyawan baru atau yang ada ekarang, keterampilan dasar yang mereka butuhkan untuk menjalankan pekerjaan mereka. Menurut Manullang dalam manajemen personalia $(2008 ; 150)$ motivasi adalah pemberian kegairahan bekerja kepada karyawan. Dengan pemberian motivasi dimaksudkan pemberian daya perangsang kepada karyawan yang bersangkutan agar karyawan tersebut bekerja dengan segala upayanya. Menurut Organ (1988; dalam Hoffman et al., 2007) Organizational Citizenship Behavior (OCB) adalah sebuah tipe spesial dari kebiasaan kerja yang mendefinisikan sebagai perilaku individu yang sangat menguntungkan untuk organisasi dan merupakan kebebasan memilih, secara tidak langsung atau secara eksplisit diakui oleh sistem penghargaan formal.

\section{Hipotesis Penelitian}

Hipotesis 1 Budaya Kerja (X1):

Ho : Budaya kerja (X1) tidak berpengaruh secara signifikan terhadap Organizational Citizenship Behavior (Y).

$\mathrm{Ha}$ : Budaya kerja (X1) berpengaruh secara signifikan terhadap Organizational Citizenship Behavior (Y) 
Hipotesis 2 Pelatihan (X2):

Ho : Pelatihan (X2) tidak berpengaruh secara signifikan terhadap Organizational Citizenship Behavior (Y).

Ha : Pelatihan (X2) berpengaruh secara signifikan terhadap Organizational Citizenship Behavior (Y).

Hipotesis 3 Motivasi (X3):

Ho : Motivasi (X1) tidak berpengaruh secara signifikan terhadap Organizational Citizenship Behavior (Y).

Ha : Motivasi (X1) berpengaruh secara signifikan terhadap Organizational Citizenship Behavior (Y).

\section{METODOLOGI PENELITIAN}

Penelitian ini dilaksanakan di Sentra Batik Giriloyo, Imogiri, Bantul, Daerah Istimewa Yogyakarta. Yang menjadi objek dalam penelitian ini adalah para pengrajin batik di Sentra Batik Giriloyo. Pengumpulan data diperoleh dengan cara menyebarkan kuisioner kepada pengrajin batik Giriloyo yang diambil sebagai sampel sebanyak 50 pengrajin batik. Penyebaran kuisioner dilakukan pada tanggal 24 -25 januari 2015.

\section{Metode Regresi Linear Berganda}

Metode ini berguna untuk mengetahui seberapa besar pengaruh budaya kerja, pelatihan, dan motivasi yaitu dalam bentuk langsung dan tidak langsung terhadap Organizational Citizenship Behavior $(O C B)$ pengrajin batik di sentra batik Giriloyo Yogyakarta. Agar hasil yang diperoleh lebih terarah, maka penulis menggunakan bantuan program software SPSS versi 16.

Persamaan regresi berganda yang digunakan adalah:

$$
\mathbf{Y}=\mathbf{a}+\mathbf{b}_{1} \mathbf{X}_{1}+\mathbf{b}_{2} \mathbf{X}_{2}+\mathbf{b}_{3} \mathbf{X}_{3}+\mathbf{e}
$$

Keterangan:

$$
\begin{array}{ll}
\mathrm{Y} & =\text { skor Organizational Citizenship Behavior }(O C B) \\
\mathrm{a} & =\text { konstanta } \\
\mathrm{b}_{1} \ldots \mathrm{b}_{3} & =\text { koefisien regresi } \\
\mathrm{X}_{1} & =\text { skor variabel budaya kerja } \\
\mathrm{X}_{2} & =\text { skor variabel pelatihan } \\
\mathrm{X}_{3} & =\text { skor variabel motivasi } \\
\mathrm{e} & =\text { standar error }
\end{array}
$$

\section{HASIL DAN PEMBAHASAN}

\section{Hasil Analisis Deskriptif}

\section{a. Budaya Kerja}

Deskripsi budaya kerja berdasarkan rata-rata skor variabelnya disajikan dalam Tabel 1 sebagai berikut :

Tabel 1

Hasil Analisis Deskriptif Variabel Budaya Kerja

\begin{tabular}{lll}
\hline \hline Kategori & $\begin{array}{l}\text { Jumlah } \\
\text { (Orang) }\end{array}$ & $\begin{array}{l}\text { Presentase } \\
\%\end{array}$ \\
\hline \hline Sangat Rendah & - & - \\
Rendah & 15 & 30,24 \\
Sedang & 22 & 43,35 \\
Tinggi & 8 & 16,15 \\
Sangat Tinggi & 5 & 10,26 \\
Jumlah & 50 & 100.00 \\
\hline \hline
\end{tabular}

Sumber : Data primer, 2016 diolah. 
Berdasarkan data yang disajikan dalam Tabel 1 tampak bahwa, dari 50 orang responden sebagian besar memberikan jawaban sedang dengan total 22 responden. Dengan demikian dapat disimpulkan bahwa, pengrajin yang menjadi responden penelitian ini memiliki budaya kerja yang tergolong sedang. Sehingga dapat dikatakan bahwa pengrajin memiliki budaya kerja yang cukup baik

\section{b. Pelatihan}

Deskripsi Pelatihan berdasarkan rata-rata skor variabelnya disajikan dalam Tabel 4.6 berikut :

Tabel 2

Hasil Analisis Deskriptif Variabel Pelatihan

\begin{tabular}{llc}
\hline \hline Kategori & $\begin{array}{l}\text { Jumlah } \\
\text { (orang) }\end{array}$ & $\begin{array}{l}\text { Persentase } \\
(\%)\end{array}$ \\
\hline \hline Sangat Rendah & - & - \\
Rendah & 6 & 12,37 \\
Sedang & 12 & 24,34 \\
Tinggi & 24 & 47,16 \\
Sangat Tinggi & 8 & 16,23 \\
Jumlah & & 100.00 \\
& & \\
\hline
\end{tabular}

Sumber: Data primer, 2016 diolah.

Berdasarkan data yang disajikan dalam Tabel 2 tampak bahwa, dari 50 orang responden sebagaian besar memberikan jawaban Tinggi dengan total 24 responden. Dengan demikian dapat disimpulkan bahwa pengrajin yang menjadi responden penelitian ini memiliki pelatihan yang tergolong tinggi. Sehingga dapat dikatakan bahwa pengrajin dapat menerima pelatihan yang diberikan.

\section{c. Motivasi}

Deskripsi motivasi berdasarkan rata-rata skor variabelnya disajikan dalam Tabel 3 berikut :

\section{Tabel 3}

Hasil Analisis Deskriptif Variabel Motivasi

\begin{tabular}{lll}
\hline \hline Kategori & $\begin{array}{l}\text { Jumlah } \\
\text { (orang) }\end{array}$ & $\begin{array}{l}\text { Persentase } \\
(\%)\end{array}$ \\
\hline \hline Sangat Rendah & - & - \\
Rendah & 11 & 19.64 \\
Sedang & 21 & 37.50 \\
Tinggi & 18 & 32.14 \\
Sangat Tinggi & 6 & 10.71 \\
$\quad$ Jumlah & 50 & \multicolumn{2}{c}{100.00} \\
\hline \hline
\end{tabular}

\section{Sumber: Data primer, 2016 diolah.}

Berdasarkan data yang disajikan dalam Tabel 3 tampak bahwa, dari 50 orang responden sebagaian besar memberikan jawaban sedang dengan total 22 responden. Dengan demikian dapat disimpulkan bahwa, pengrajin yang menjadi responden penelitian ini memiliki motivasi yang tergolong sedang. Sehingga dapat dikatakan bahwa pengrajin memiliki motivasi untuk bekerja. 


\section{d. Organizational Citizenship Behavior}

Deskripsi Organizational Citizenship Behavior pengrajin berdasarkan rata-rata skor variabelnya disajikan dalam Tabel 4.

Tabel 4

Hasil Analisis Deskriptif Variabel Organizational Citizenship Behavior

\begin{tabular}{|c|c|c|}
\hline Kategori & $\begin{array}{l}\text { Jumlah } \\
\text { (orang) }\end{array}$ & $\begin{array}{l}\text { Persentase } \\
(\%)\end{array}$ \\
\hline Sangat Rendah & - & - \\
\hline Rendah & 15 & 30,19 \\
\hline Sedang & 28 & 46,21 \\
\hline Tinggi & 4 & 8,38 \\
\hline Sangat Tinggi & 3 & 6,22 \\
\hline Jumlah & 50 & 100.00 \\
\hline
\end{tabular}

Sumber: Data primer, 2016 diolah.

Berdasarkan data yang disajikan dalam Tabel 4 tampak bahwa, dari 50 orang responden sebagian besar memberikan jawaban sedang dengan total 28 responden. Dengan demikian dapat disimpulkan bahwa pengrajin yang menjadi responden penelitian ini memiliki rasa Organizational Citizenship Behavior yang tergolong sedang.

\section{Hasil Analisis Inferensial}

Analisis inferensial digunakan untuk melakukan analisis data sampel dan hasilnya diberlakukan untuk populasi. Teknik analisis inferensial dilakukan untuk meneliti pengaruh variabel independen tehadap variabel dependen.

\section{a. Model Persamaan}

Untuk melihat hasil analisis pengaruh dari ketiga variabel independen (X) terhadap variabel dependen (Y) terdapat pada tabel 5 pada kolom Beta dibawah standardized coefficients.

Tabel 4.15

Hasil Analisis Regresi Berganda

Coefficients $^{\mathrm{a}}$

\begin{tabular}{|c|c|c|c|c|c|c|}
\hline \multirow{2}{*}{\multicolumn{2}{|c|}{ Model }} & \multicolumn{2}{|c|}{$\begin{array}{l}\text { Unstandardized } \\
\text { Coefficients }\end{array}$} & \multirow{2}{*}{$\begin{array}{c}\text { Standardized } \\
\text { Coefficients } \\
\text { Beta }\end{array}$} & \multirow[b]{2}{*}{$\mathrm{t}$} & \multirow[b]{2}{*}{ Sig. } \\
\hline & & B & Std. Error & & & \\
\hline \multirow[t]{4}{*}{1} & (Constant) & 3.235 & 6.345 & & .510 & .613 \\
\hline & $\mathrm{X} 1$ & -.065 & .087 & -.094 & -.746 & .460 \\
\hline & $\mathrm{X} 2$ & .472 & .155 & .390 & 3.047 & .004 \\
\hline & $\mathrm{X} 3$ & .245 & .114 & 274 & 2.138 & .038 \\
\hline
\end{tabular}

a. Dependent Variable: Y

Sumber: Data primer, 2016 diolah.

Dari tabel 4.15 dapat dilihat nilai Beta dari nilai X1 (Budaya Kerja) $=-.094$ nilai X2 $($ Pelatihan $)=0.390$ dan nilai X3 (Motivasi) $=0.274$. Dengan demikian persamaan regresi linear berganda adalah

$$
\mathrm{Y}=-.094 \mathrm{X} 1+0.390 \mathrm{X} 2+-0.274 X 3+\mathrm{e} .
$$




\section{b. Koefisien Determinan $\left(\mathbf{R}^{2}\right)$ dan Uji F}

Koefisien determinan merupakan besarnya pengaruh variabel independen secara simultan yang menjelaskan variabel dependen dalam persamaan regresi. Besarnya $\mathrm{R}^{2}$ berada pada nilai 0 (nol) sampai dengan1 (satu). Semakin mendekati angka 1 maka semakin besar pengaruhnya.

\section{Tabel 6}

\section{Hasil Uji Koefisien determinan $\mathbf{R}^{2}$}

\begin{tabular}{|c|c|c|c|c|}
\hline Model & $\mathrm{R}$ & R Square & $\begin{array}{l}\text { Adjusted R } \\
\text { Square }\end{array}$ & $\begin{array}{l}\text { Std. Error of } \\
\text { the Estimate }\end{array}$ \\
\hline 1 & $.529^{\mathrm{a}}$ & .279 & .232 & 4.85419 \\
\hline \multicolumn{5}{|c|}{ a. Predictors: (Constant), X3, X1, X2 } \\
\hline \multicolumn{5}{|c|}{ b. Dependent Variable: Y } \\
\hline
\end{tabular}

\section{Sumber: Data primer, 2016 diolah}

Dari tabel 6 diketahui bahwa variabel independen mempengaruhi variabel dependen sebesar 0,232 dilihat dari kolom Adjusted $R$ Square. Hal ini dapat diartikan bahwa variabel dependen X1 (Budaya Kerja), X2 (Pelatihan), dan X3 (Motivasi) yang dimiliki mempengaruhi variabel dependen Y (Organizational Citizenship Behavior) sebesar 23,2 $\%$. Hal ini menunjukkan bahwa masih ada faktor-faktor lain yang mempengaruhi Organizational Citizenship Behavior pada pengrajin batik di Sentra Batik Giriloyo, Bantul, Yogyakarta sebesar 76,8\%.

Uji simultan (Uji F) digunakan untuk mengetahui pengaruh semua variabel independen yang dimasukkan dalam model regresi secara simultan terhadap variabel dependen yang diuji pada tingkat signifikan 0,05. Hasil uji statistik F dapat dilihat pada tabel 7.

Tabel 7

Hasil Uji Simultan (Uji F)

\begin{tabular}{lllllll}
\hline \hline Model & & $\begin{array}{l}\text { Sum of } \\
\text { Squares }\end{array}$ & Df & Mean Square & F & Sig. \\
\hline \hline 1 & Regression & 420.425 & 3 & 140.138 & 5.947 & $.002^{\text {a }}$ \\
& Residual & 1083.905 & 46 & 25.563 & & \\
& Total & 1504.320 & 49 & & & \\
\multicolumn{2}{ll}{ a. Predictors: (Constant), X3, X1, X2 } & & & \\
\hline \hline
\end{tabular}

\section{Sumber: Data primer, 2016 diolah}

Hasil Uji Hipotesis 4 :

Pengaruh variabel independen X1 (Budaya Kerja), X2 (Pelatihan), dan X3 (Motivasi) terhadap variabel dependen Y (Organizational Citizenship Behavior). Hasil uji hipotesis dapat dilihat pada tabel diatas, nilai $\mathrm{F}$ diperoleh sebesar 5.947 dengan tingkat kesalahan $5 \%$, dimana $\mathrm{F}$ tabel $=2,81$ ternyata $\mathrm{F}$ hitung $>\mathrm{F}$ tabel $(5.947>2,81)$, dengan demikian $\mathrm{F}$ hitung $>\mathrm{F}$ tabel sehingga $\mathrm{H0}$ ditolak dan Ha diterima, ini menunjukkan bahwa secara simultan antara variabel independen X1 (Budaya Kerja), X2 (Pelatihan), dan X3 (Motivasi) berpengaruh terhadap variabel dependen Y (Organizational Citizenship Behavior) 


\section{c. Koefesien Regresi ( $\beta$ ) dan Uji t}

Uji t dikenal dengan uji parsial, yaitu untuk menguji bagaimana pengaruh masing-masing variabel bebas terhadap variabel terikat. Uji ini dapat dilakukan dengan melihat kolom signifikansi.

Tabel 4.19

Hasil Analisis Koefesien Regresi ( $\beta$ ) dan Uji t

\begin{tabular}{|c|c|c|c|c|c|c|}
\hline \multirow[b]{2}{*}{ Model } & & \multicolumn{2}{|c|}{ Unstandardized Coefficients } & \multicolumn{2}{|c|}{$\begin{array}{l}\text { Standardized } \\
\text { Coefficients }\end{array}$} & \multirow[b]{2}{*}{ Sig. } \\
\hline & & B & Std. Error & Beta & $\mathrm{T}$ & \\
\hline \multirow[t]{4}{*}{1} & (Constant) & 3.235 & 6.345 & & .510 & .613 \\
\hline & $\mathrm{X} 1$ & -.065 & .087 & -.094 & -.746 & .460 \\
\hline & $\mathrm{X} 2$ & .472 & .155 & .390 & 3.047 & .004 \\
\hline & $\mathrm{X} 3$ & .245 & .114 & .274 & 2.138 & .038 \\
\hline \multicolumn{7}{|c|}{ a. Dependent Variable: Y } \\
\hline
\end{tabular}

Sumber: Data primer, 2016 diolah

Nilai signifikansi variabel X1 (Budaya Kerja) sebesar 0,460 > dari signifikansi 0,05. Dengan demikian Ho diterima dan Ha ditolak. Oleh karena itu dapat dikatakan bahwa Budaya Kerja (X1) tidak berpengaruh secara signifikan terhadap Y (Organizational Citizenship Behavior)

Nilai signifikansi variabel X2 (Pelatihan) sebesar 0,004< dari signifikansi 0,05. Dengan demikian Ho ditolak dan Ha diterima. Oleh karena itu dapat dikatakan bahwa Pelatihan (X2) berpengaruh secara signifikan terhadap Y (Organizational Citizenship Behavior)

Nilai signifikansi variabel X3 (Motivasi) sebesar 0,038< dari signifikansi 0,05. Dengan demikian Ho ditolak dan Ha diterima. Oleh karena itu dapat dikatakan bahwa Motivasi (X1) berpengaruh secara signifikan terhadap Y (Organizational Citizenship Behavior)

\section{SIMPULAN}

1. Budaya kerja tidak berpengaruh secara signifikan terhadap Organizational Citizenship Behavior dengan tingkat signifikansi 0,460> $>0.05$. Hal ini memberikan implikasi bahwa budaya kerja tidak menumbuhkan rasa Organizational Citizenship Behavior para pengrajin batik.

2. Pelatihan berpengaruh secara signifikan terhadap Organizational Citizenship Behavior dengan tingkat signifikansi $0,04<\alpha 0,05$. Hal ini memberikan implikasi bahwa dengan adanya pelatihan maka menumbuhkan rasa Organizational Citizenship Behavior para pengrajin batik.

3. Motivasi berpengaruh secara signifikan terhadap Organizational Citizenship Behavior dengan tingkat signifikansi $0,036<\alpha 0,05$. Hal ini memberikan implikasi bahwa motivasi yang dimiliki para pengrajin batik menumbuhkan Organizational Citizenship Behavior para pengrajin batik.

4. Secara simultan variabel budaya kerja, pelatihan, dan motivasi berpengaruh signifikan terhadap Organizational Citizenship Behavior 


\section{REFERENSI}

Arep, Ishak., dan Hendri Tanjung. 2003. Manajemen Motivasi. PT.Gramedia Widiasarana Indonesia. Jakarta

Besterfield, Dale H. 2003. Total Quality Manajemen. Prentice hall. New Jersey.

Dessler, Gary. 2004. Manajemen Sumber Daya Manusia. Edisi Bahasa Indonesia. Jilid 2. PT Prehallindo. Jakarta.

Ghozali, Imam. 2006. Aplikasi Analisis Multivariate Dengan Program SPSS. Badan Penerbit Universitas Diponegoro. Semarang.

Gomes, Faustino Cordoso. 1995. Manajemen Sumber Daya Manusia. Penerbit Andi. Yogyakarta

Gunawan. 2001. Manajemen Jilid 2. Erlangga. Jakarta.

Handoko, T. Hani. 2001. Manajemen personalia dan sumber daya manusia. BPFE.Yogyakarta.

Hardjana, A.M. 2001. Training SDM yang Efektif. Kanisius. Yogyakarta.

Hoffman, Et Al. 2007. "Expanding the Criterion Domain? A Quantitative Review of the OCB Literature". Journal Of Applied Psychology, 92, 555-566.

Koentjaraningrat. 2004. Kebudayaan Mentalitet dan Pembangunan. Gramedia. Jakarta.

Mahendra, Rully. 2009. Pengaruh Kepuasan Kerja, Komitmen Organisasi dan Lingkungan Kerja terhadap Organizational Citizenship Behavior (OCB) Pegawai Bagian Umum Kantor Sekretariat Daerah Kabupaten Semarang. Jurnal Ilmu Pendidikan. (http://id.linkedin.com/pub/rully-mahendra/22/23a/477).

Mangkunegara, A. A. Anwar Prabu. 2005. Manajemen Sumber Daya Manusia Perusahaan. Remaja Rosda Karya. Bandung.

Manullang, M, dan Marihot AMH Manullang. 2008. Manajemen Personalia. Edisi Ke-3. Gadjah Mada University Press. Yogyakarta.

Mathis, Robert L, dan John H. Jackson. 2001. Manajemen Sumber Daya Manusia. Salemba Empat. Jakarta.

Moekijat. 2006. Asas-Asas Perilaku Organisasi. CV. Mandar Maju. Bandung.

Nawawi, Hadari. 2003. Manajemen Sumber Daya Manusia. Cetakan kelima. Gajah Mada University Press. Yogyakarta.

Ndraha ,Taliziduhu. 2003. Teori Budaya Organisasi. Cetakan Kedua. PT. Rineka Cipta. Jakarta.

Nitisemito, Alex. 2000. Manajemen Personalia. Penerbit Ghalia Indonesia. Jakarta.

Osborn dan Plastrik.2002. Manajemen Sumber Daya Manusia. BPFE.Yogyakarta.

Purwono, Moh. 2001. Manajemen Personalia. Edisi Ketiga. Erlangga. Jakarta.

Restiana, Merry. 2013. "Pengaruh Komitmen Organisasi dan Kepuasan Kerja Terhadap Organizational Citizenship Behaviour Pada Rumah Sakit Bhayangkara Tridjata Denpasar". DiE Jurnal Ekonomi dan Manajemen Volume 9 No 1

Rini, D.P, Rusdarti dan Suparjo. 2013. "Pengaruh komitmen organisasi, kepuasan kerja dan budaya organisasi terhadap Organizational Citizenship Behavior (OCB)". Jurnal Ilmiah Dinamika Ekonomi Dan Bisnis, Vol.1 No. 1. 
Saragih, R dan Joni. 2007. "Individualism-Collectivism (ic) As An Individual Difference Predictor Of Organizational Citizenship Behavior (OCB) In An Accounting Environment Setting”. Jurnal Manajemen Universitas Kristen Maranatha Bandung; Volume 6, No.2, Mei 2007.

Sarwoto. 2000. Dasar-Dasar Organisasi dan Manajemen. Ghalia. Jakarta.

Simmamora, Henry. 2006. Manajemen sumber daya manusia. STIE YKPN. Yogyakarta.

Sugiyono. 2006. Metode Penelitian Bisnis. Alfabeta. Bandung.

Triguno. Prasetya. 2001. Manajemen Sumber Daya Manusia. Bumi Aksara. Jakarta.

Widagdho, Djoko. 2004. Ilmu Budaya Dasar. Cetakan Kesembilan. PT. Bumi Aksara. Jakarta 